Research paper

\title{
A multilevel perspective to explain recycling behaviour in communities
}

\author{
Carmen Tabernero ${ }^{\mathrm{a},{ }^{*}}$, Bernardo Hernández ${ }^{\mathrm{b}}$, Esther Cuadrado ${ }^{\mathrm{a}}$, Bárbara Luque ${ }^{\mathrm{a}}$, \\ Cícero R. Pereira ${ }^{\mathrm{c}}$ \\ a University of Córdoba, Department of Psychology, Avenida San Alberto Magno s/n, 14004 Córdoba, Spain \\ ${ }^{\mathrm{b}}$ University of La Laguna, Department of Social Psychology, Campus de Guajara, 38071 La Laguna, Tenerife, Spain \\ ${ }^{c}$ Institute of Social Sciences, University of Lisbon, Av. Prof. Anibal de Bettencourt, 9, 1600-189 Lisbon, Portugal
}

\section{A R T I C L E I N F O}

\section{Article history:}

Received 17 June 2014

Received in revised form

13 May 2015

Accepted 19 May 2015

Available online 14 June 2015

\section{Keywords:}

Multilevel

Self-efficacy

Community efficacy

Satisfaction with service quality

Recycling behaviour

\begin{abstract}
A B S T R A C T
Previous research on the motivation for environmentally responsible behaviour has focused mainly on individual variables, rather than organizational or collective variables. Therefore, the results of those studies are hardly applicable to environmental management. This study considers individual, collective, and organizational variables together that contribute to the management of environmental waste. The main aim is to identify, through the development of a multilevel model, those predictive variables of recycling behaviour that help organizations to increase the recycling rates in their communities. Individual (age, gender, educational level, self-efficacy with respect to residential recycling, individual recycling behaviour), organizational (satisfaction with the quality of the service provided by a recycling company), and collective (community recycling rates, number of inhabitants, community efficacy beliefs) motivational factors relevant to recycling behaviour were analysed. A sample of 1501 residents from 55 localities was surveyed. The results of multilevel analyses indicated that there was significant variability within and between localities. Interactions between variables at the level of the individual (e.g. satisfaction with service quality) and variables at the level of the collective (e.g. community efficacy) predicted recycling behaviour in localities with low and high community recycling rates and large and small populations. The interactions showed that the relationship between self-efficacy and recycling is stronger in localities with weak community efficacy beliefs than in communities with strong beliefs. The findings show that the relationship between satisfaction with service quality and recycling behaviour is stronger in localities with strong community efficacy beliefs than in communities with weaker beliefs and a smaller population. The results are discussed accordingly in relation to theory and possible contribution to waste management. Those findings may be incorporated in national and international environmental policies in order to promote environmentally responsible behaviour in citizenship.
\end{abstract}

(C) 2015 Elsevier Ltd. All rights reserved.

\section{The importance of recycling in communities}

For many years, public concern over the environment protection has been not only local or national but also international. Environmental protection may ensure sustainable development throughout the world. In this sense, while most national and international environmental policies and politics have been adopted, unsustainable trends persist and nations still need to employ

\footnotetext{
* Corresponding author.

E-mail addresses: carmen.tabernero@uco.es (C. Tabernero), bhdezr@ull.es (B. Hernández), esther.cuadrado@uco.es (E. Cuadrado), b.luque@uco.es (B. Luque), cicero.pereira@ics.ul.pt (C.R. Pereira).
}

greater effort in order to meet their aspirations (Jordan and Lenschow, 2010). Accordingly, persuading individuals, groups, communities, collectives and companies to adopt environmentally responsible behaviour (ERB) has become one of society's main priorities and this is reflected in support for actions at a micro level (e.g. buying energy efficient appliances) and proposals incorporated into major international political agreements (e.g. the signing of the Kyoto Protocol). This interest is manifested in various ways, although they usually share the aim of promoting proenvironmental sensitivity and awareness in society as a whole. For example, environmental concern has helped to promote environmental education programmes (Oskamp, 2002). Moreover, although many studies have been published about the effectiveness 
and efficiency of a variety of policy instruments regarding the collection and treatment of household waste, it is noteworthy that the information is complex, often contradictory and difficult to interpret (Gellynck et al., 2011). Consequently, one of the challenges facing applied social studies today is to explain and predict what motivates individuals, groups and communities to engage in ERB and share their resources for the common environmental good. In turn, at a more practical level, this kind of research may allow more accurate national and international policies and actions that are oriented to promoting pro-environmental behaviour.

As a result of interest in ERB, in recent years an increasing number of researchers have attempted to identify variables that predict ERB (e.g. Gifford, 2013; Juárez-Lugo, 2010; Milfont and Page, 2013; Turaga et al., 2010). Several meta-analyses (e.g. Bamberg and Möser, 2007; Osbaldiston and Schott, 2012) have shown that sociodemographic variables, such as gender, age and education level, have an effect on ERB. The meta-analyses indicate that nearly all psychological states have been put forward at some point as antecedents of, or motives for, ERB. Research has shown that selfefficacy is a motivational variable, i.e. it influences the occurrence of specific behaviours; in this sense self-efficacy also predicts ERB, however, this variable has received little attention in relation to ERB (Tabernero and Hernández, 2011).

Kollmus and Agyeman (2002), identified factors that influence ERB; they considered that both internal and external factors influence ERB and thus external (e.g. institutional, economic, social, and cultural) as well as internal variables must be included in research. External variables have been neglected in much of the psycho-environmental research on ERB, although some studies have shown that there are external factors that influence whether communities act ecologically or not (Blake, 1999). Similarly, Steg and Gifford (2005) reported that structural inadequacies, such as a lack of availability of recycling facilities, constrained ERB, and Kollmus and Agyeman (2002) suggested that many ERBs, such as recycling, can only take place if the necessary infrastructure is provided; the poorer such services, the less likely people are to use them. Corral-Verdugo (2012) found that satisfaction with infrastructural and economic factors was related to recycling behaviour. Chen and Tung (2010) also found evidence that consumers' perceptions of lack of facilities decreased their intention to recycle. We therefore hypothesised that if people perceive a recycling service to be poor and are dissatisfied with it they will be less likely to use it and, in consequence, levels of recycling will be lower, both at an individual level and at community level. This study therefore examined the role in recycling behaviour of an external factor which has not been previously explored, customer satisfaction with the quality of service provided by the recycling company.

Schultz et al. (2013) recently argued that it is necessary to use multilevel analysis to study ERB, investigating both personal and contextual determinants. Using a multilevel perspective, Guerin et al. (2001) analysed the social and institutional factors that interacted with a series of individual variables to influence recycling behaviour in different countries. Gelissen (2007) also argued that it is necessary simultaneously to assess the effects of individual and contextual variables on ERB. The importance of a multilevel approach to this field has been recognised, more multilevel studies are required to explore how individual and collective factors combine to influence recycling behaviour. Our study addresses this gap in the published literature on recycling.

Socio-demographic and attitudinal variables associated with ERB have also been investigated [e.g. Scannell and Gifford (2013) found that women reported more strongly pro-environmental attitudes than men]. Pirani and Secondi (2011) studied differences in pro-environmental behaviours between European countries. Using a multilevel design, they investigated pro-environmental attitudes, including as covariates socio-demographic and socio-economic variables. They found a high level of eco-friendly behaviour in women, middle-aged and elderly people, and individuals with a higher level of education. We therefore chose to examine the role of socio-demographic variables (e.g. gender, age and educational level) in recycling behaviour from a multilevel perspective. Pirani and Secondi (2011) also concluded that living in a large town, rather than in a small or medium-sized town, was negatively associated with the probability of reducing energy consumption and, like other pro-environmental acts, was positively associated with the probability of choosing an eco-friendly way of travelling and buying eco-friendly products. Research from a different culture (Chen et al., 2013)found an opposite result, residents of larger cities of China were more likely to engage in pro-environmental behaviours than were residents of smaller cities. We therefore included community size (i.e. number of inhabitants) as a collective level variable in our general multilevel model; we predicted that number of inhabitants would be negatively associated with individual recycling.

In addition to service satisfaction and number of inhabitants variables, in this study a multilevel approach was applied to selfefficacy; its role in recycling was examined from two perspectives: self-efficacy at the individual level and community efficacy at the collective level. Incorporating self-efficacy in our model of recycling behaviour helps to establish a link between the two levels of analysis: individual (self-efficacy) and collective (community efficacy), as well as having theoretical relevance and addressing a gap in current research. From an integrative point of view, the construct of self-efficacy explains how people's reactions to different situations including new, complex and challenging tasks such as deciding to establish a new recycling system in the home, changing energy consumption habits, or modifying personal mobility patterns by changing from private to public transport and/ or less contaminating modes of transport (Bandura, 2002; Tabernero and Hernández, 2011, 2012). Self-efficacy and community efficacy beliefs are defined as perceptions about the level of personal or community competence required and available to carry out a certain behaviour. Sampson, Raudenbush and Earls (1997, p. 919) described community efficacy within neighbourhoods as "the linkage of mutual trust and the willingness to intervene for the common good".

When behaviour is analysed from a community perspective, the social comparison process is considered a generator of behaviour. This study explores the motivational influence of self-efficacy and community efficacy beliefs with respect to recycling and community recycling rates on individuals' recycling behaviour through social comparison processes or observation of others. Lindsley, Brass, and Thomas (1995) argued that social change is a product of efficacyperformance spirals in individuals, groups, communities and organisations; the advantage of a multilevel perspective is that it recognises that individuals, groups, communities and organisations are not separate conceptual categories but parts of a whole, each part affecting, and being affected by, the others. In this study, efficacy-performance spirals in individuals and communities are conceptualised as the result of interactions between self-efficacy, community efficacy and community recycling rates.

\section{A multilevel theoretical model and hypotheses}

In the present research, a multilevel study was conducted to analyse collective (e.g. number of inhabitants, community efficacy, community recycling rates) and individual (e.g. age, gender, educational level, satisfaction with service quality, self-efficacy) factors that potentially explain recycling behaviour. The multilevel model and specific hypotheses tested in this study are summarised in Fig. 1. Factors presented in this model could be 
considered as national and international indicators for planning political interventions.

We hypothesised that at the individual level satisfaction with service quality and self-efficacy would be positively associated with personal recycling behaviour, exerting influence partly via collective level variables. Similarly, at the collective level, community efficacy and community recycling rate were predicted to be positively associated with recycling, whereas number of inhabitants was predicted to be negatively associated with recycling behaviour. We also considered influences that cross-levels, including direct, mediated and moderating cross-level effects of individual and collective variables. In this theoretical model socio-demographic variables are related to recycling. A considerable body of research has attempted to identify socio-demographic factors (such as age, gender and educational level) related to participation in recycling, (e.g. Scannell and Gifford, 2013; Vining and Ebreo, 1990); we developed the following specific hypotheses:

Hypothesis 1. Socio-demographic factors will be related to recycling behaviours; older people, women and those educated to a higher level will recycle more than younger people $(H 1 a)$, males $(H 1 b)$, and those educated to a lower level (H1c).

\subsection{Satisfaction with recycling service quality}

Perceived service quality is defined as a subjective evaluation of service excellence which is directly associated with customer loyalty and organisational productivity (Bruhn and Georgi, 2006). Grönroos (1984) considered that the dimension 'functional quality'-which reflects how the service is provided, as well as the nature and mechanism of the interaction between service providers and customers-is a crucial element of perceived service quality.

Customer satisfaction affects customer behaviour; according to Reicheld (1996), customer satisfaction is an antecedent of both customer loyalty and customer behaviour. The present study evaluated satisfaction with the service provided by a recycling company. Satisfaction can be related to factors associated with the quality of the service provided by staff (timeliness, responses, friendliness) and the quality of the product (number of containers, cleaning, collection times). This study sought to investigate whether satisfaction with service quality is related to individuals' recycling behaviour. In accordance with the theoretical framework discussed above we proposed the following hypothesis:

Hypothesis 2. Individuals who are highly satisfied with the quality of a recycling service will recycle more than individuals who are less satisfied with the quality of the service.

\subsection{Self- and community efficacy towards recycling behaviour}

Bandura (2002) maintained that of the different behavioural self-regulation mechanisms, self-efficacy was the best predictor of whether an individual would choose to get involved in an activity, particularly where the activity required significant personal effort. Self-efficacy can be defined as a belief in one's own capacity to organise and undertake the action required to cope with certain situations in the near future (Bandura, 1997); it is a self-regulatory mechanism that motivates an individual to make more effort and persist in the face of adversity in order to achieve an anticipated goal. Based on social cognitive theory, Bandura (2000) has extended the concepts of self-efficacy and human agency to encompass community efficacy and community agency. Bandura (1997) presented community efficacy and perceived community efficacy as constructs that can explain community motivation. Perceived community efficacy describes people's beliefs about their ability successfully to accomplish specific tasks within their community. Confidence in community efficacy determines perceptions of a group's goal or purpose, the intensity of a group's commitment to those goals, mutual understanding and empathy within the

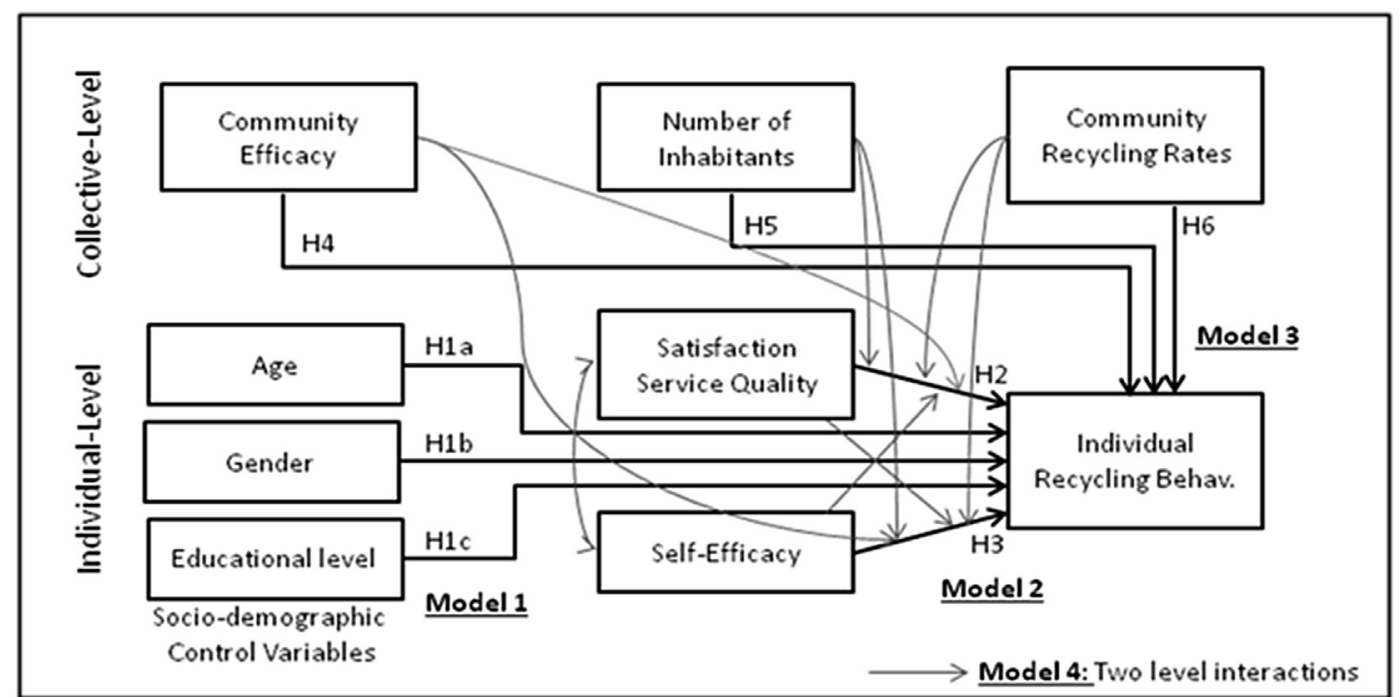

In model 1, all sociodemographic variables (age $\mathrm{H} 1 \mathrm{a}$, gender $\mathrm{H} 1 \mathrm{~b}$, and educational level $\mathrm{H} 1 \mathrm{c}$ ) are inserted as predictors of individual recycling behavior. In model 2, satisfaction with service quality (H2) and self-efficacy (H3) are also inserted as predictors of individual recycling behavior. In model 3, the collective level variables (community efficacy $\mathrm{H} 4$, number of inhabitants $\mathrm{H} 5$, and community recycling rates $\mathrm{H} 6$ ) are inserted as predictor of individual recycling behaviors. In model 4, all the two level interactions are considered as predictors of individual recycling behavior.

Fig. 1. Multilevel model for environmental recycling behavior at individual and collective levels. 
group relating to achievement of satisfactory results, and persistent pursuit of goals in the face of adversity (Bandura, 1997). Bandura (2000) argued that community efficacy serves similar functions and operates through similar processes to self-efficacy; following this theoretical framework, shared beliefs about the community's efficacy with respect to recycling behaviour will influence, for example, how the community will uses its resources, how much effort the community will expend to achieve its recycling goals, the community's vulnerability to discouragement of recycling, and its intention to behave in more or less pro-environmental way.

Although the concepts of self-efficacy and perceived community efficacy may be related, they are independent constructs (Bandura, 2000). Judgements about personal efficacy can influence judgments of group and community efficacy, both directly and indirectly (Bandura, 1997). Self-efficacy and community efficacy have been included in this study as predictor variables because both are powerful predictors of behaviour. Although the impact of selfefficacy on self-reported behaviours has been widely studied in the past, its role in recycling, from a multilevel perspective, has not been investigated. In fact there has been no previous multilevel investigation of the relationship between community efficacy and recycling. Moreover, Watson et al. (2001) have pointed out that efficacy studies generally focus on a single level of analysis, and are thus subject to fundamental biases. These authors argued that there is a need for more research investigating self- and community efficacy simultaneously, and that such research might contribute to a better, more powerful and more integrated theory of efficacy. Although there may have been some multilevel studies in the proenvironmental field exploring self- and collective efficacy simultaneously, there is to our knowledge no study which has analysed recycling in terms of both self- and community efficacy; our study addresses this gap in the literature.

Gist (1987) suggested three methods for assessing community efficacy. The method used in this study defines community efficacy as the aggregate of individual perceptions of self-efficacy. This method is suitable because, as Bandura (1997) and Zaccaro et al. (1995) claimed, community efficacy can be measured as the sum of group members' individual perceptions of self-efficacy (the aggregation method) when there is no member interdependence in the relevant group tasks, as is the case for residential recycling.

Sampson et al. (1997) claimed that societies with higher perceived community efficacy achieve a more change in their suburban areas, for example, a society will make more effort to change social policies if it has a stronger belief in its capacity to change and control the social environment (Bandura, 2002). The strong theoretical framework underpinning the studies discussed above suggests that there should be a positive relationship between self- and community efficacy with respect to recycling, and an interaction between efficacy and number of inhabitants.

Socially shared opinions seem to influence the probability of action. In relation to this, Guerin et al. (2001) found that global environmental concern had a positive impact on individual propensity to recycle. Studies on the effects of social norms (Cialdini et al., 2006; Cialdini et al., 1990) have shown that making participants focus on the frequency of a behaviour - eg. being more likely to throw rubbish onto a dirty rather than a clean floor-increases the occurrence of this behaviour. Similarly, Corral-Verdugo et al. (2002) found that when others are perceived to be wasting water, fewer reasons for conservation are cited and water consumption is higher. In another series of studies Hernández et al. (2010) and Martín et al. (2014) found that if people think that others are performing an illegal anti-ecological behaviour, they are more likely to do so themselves.

Based on the above evidence, we proposed the following specific hypotheses:
Hypothesis 3. Individuals with high self-efficacy will recycle more than individuals with lower self-efficacy.

Hypothesis 4. Communities with high community efficacy will recycle more than those with lower community efficacy.

Hypothesis 5. Communities with a small population will recycle more than larger communities.

Hypothesis 6. Communities with high community recycling rates will contain individuals with higher levels of personal recycling than those with lower community recycling rates.

\subsection{Cross-level relationships}

In this study, three cross-level interactions between individual variables (self-efficacy, satisfaction service quality) and collective variables (community efficacy, number of inhabitants, community recycling rate) that we expected to predict recycling behaviour are depicted in Fig. 2.

As Bandura (2000) explained, groups with talented individual members can still perform poorly as a community. High individual self-efficacy can coexist with low community efficacy, and vice versa (Goddard and Goddard, 2001). Self- and community efficacy combine to affect individual behaviour (Bandura, 2000; Goddard and Goddard, 2001). It has also been demonstrated that self-efficacy predicts collective efficacy (Gibson, 2003; Watson et al., 2001). Goddard and Goddard (2001) claimed that collective efficacy can enhance or attenuate self-efficacy, agreeing with Bandura's (1997, p. 469) statement that individuals "are not social isolates immune to the influence of those around them". They argued that individuals are aware of and influenced by community beliefs, and concluded that collective and self-efficacy probably have a reciprocal relationship, and therefore a change in one may cause change in the other. Accepting the reciprocity of self- and collective efficacy (Goddard and Goddard, 2001), and assuming that self-efficacy is an important determinant of the extent of ERB (Bandura, 2002; Tabernero and Hernández, 2011, 2012), it is a short step to supposing that an individual's perception of his or her community's recycling efficacy would modify his or her personal recycling behaviour. In other words, an individual with low self-efficacy with respect to recycling might recycle more if he or she belonged to a community with a collective belief in the community's recycling capability; conversely, the same individual - or indeed an individual with high self-efficacy with respect to recycling - would recycle less if submerged in a community with low community efficacy with respect to recycling. We therefore proposed that community efficacy mediates the relationship between self-efficacy and individual recycling.

Consumer satisfaction has been explored in relation to products, services, infrastructures and networks; for community recycling rates, we predicted an interaction between community efficacy beliefs and satisfaction with service quality because we hypothesised that individuals (as potential consumers for the recycling company) would need to be confident in the efficacy of other members of their community to carry out residential recycling. We predicted that lack of trust in other community members would discourage individuals from acting pro-environmentally. Kollmuss and Agyeman (2002) have previously hypothesised that in order to act pro-environmentally individuals must look further than their own interests and be concerned about their locality.

This study tested the following cross-level hypotheses, derived from the theory and research described above.

Hypothesis 7. Individuals living in communities with high self- and community efficacy will show higher levels of personal recycling to protect the environment than individuals living in communities with 


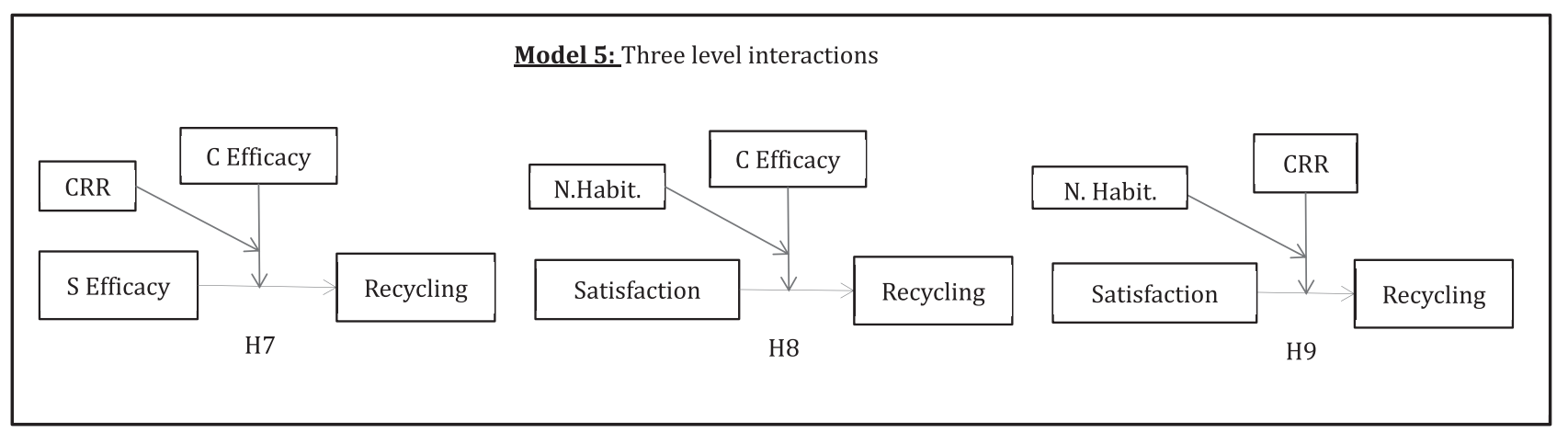

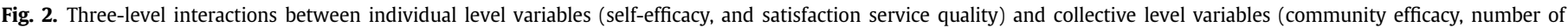
inhabitants, and community recycling rate) to predict recycling behaviour.

weaker community efficacy; both community efficacy and community recycling rates will act as covariates in the relationship between selfefficacy and individual recycling behaviour.

Hypothesis 8. Individuals living in communities with high satisfaction with service quality and strong community efficacy will show higher levels of recycling than individuals living in communities with lower levels of satisfaction and weaker community efficacy; both community efficacy and socio-demographic variables will act as covariates in the relationship between satisfaction with service quality and individual recycling behaviour.

Hypothesis 9. Individuals living in communities with high satisfaction with service quality and high community recycling rates will show higher levels of recycling than individuals living in communities with lower levels of satisfaction and community recycling rates; both community recycling rates and socio-demographic variables will act as covariates in the relationship between satisfaction with service quality and individual recycling behaviour.

\section{Method}

\subsection{Physical context}

This study was conducted in Córdoba, a province of southern Spain covering $13,769 \mathrm{~km}^{2}$, with a total population of 803,038 inhabitants. In the capital city Córdoba, the recycling service is managed by the City Council. In the other towns, the recycling service is managed by a public organisation. This research was carried out in 55 of the 74 towns where the recycling service is managed by that public organisation.

The populations of the 55 towns selected ranged from 410 to 39,783 inhabitants and from 131 to 13,086 households. The mean population was $6072.67(S D=7355)$. The remaining 19 towns were not included because they have fewer than 400 citizens. The public organisation provided information about the number of glass $(M=13.04 ; S D=13.84 ;$ range $=1-67)$ and paper $(M=13.55$; $S D=13.53$; range $=2-58$ ) recycling containers available in each community.

This research is part of a study of residents' attitudes towards their current recycling services and habits relating to recycling and waste collection in general and was commissioned by the public organisation responsible for waste management in the municipalities of the province of Córdoba.

\subsection{Participants}

A questionnaire was administered to 1501 individuals selected at random from a population of 361,168 inhabitants $(120,389$ households) distributed across 55 localities in Córdoba, Spain. The majority of the participants (72.1\%) were women and the sample was categorised into four age groups: under 30 years $(29.92 \%)$, 31-50 years (28.75\%), 51-65 years (19.91\%) and over 66 years (21.42\%). Questions asked about participants' educational level and their employment status (at the time of the study, $43.1 \%$ of the participants in the sample were employed, $23.4 \%$ were retired, $17.2 \%$ worked at home, $12.1 \%$ were students, and $4.2 \%$ were unemployed). Educational level was categorised as follows: $1=$ none or did not finish elementary school study (16.6\%), 2 = completed elementary school (35.9\%), 3 = junior high school study (23.1\%), $4=$ high school study (10.8\%) and $5=$ university or further study (10.8\%); $2.8 \%$ of respondents did not answer this question.

The sample used in this study is representative of the population in this region of southern Spain. The National Statistics Institute (INE, 2013) published age data for the population in this area: considering only people over 17 years old, percentages for the four age categories we used are: under 30 years (22.34\%), 31-50 years (37.41\%), 51-65 years, (20.03\%), and over 66 years (20.22\%).

\subsection{Task and procedure}

Four team members were trained to administer the questionnaires in the 55 localities. They carried identification as university research collaborators. On arrival in a locality two of the team began to collect data from the city centre to the suburbs; the other two worked from the suburbs to the city centre, in order to cover the whole area. The data collection phase lasted two months. Administrators visited participants' homes to administer the household questionnaire: they were instructed to knock on residents' doors throughout the assigned area and ask if the resident was willing to be interviewed (only a small number of residents refused to participate). The average time taken to complete the questionnaire was $30 \mathrm{~min}$. Questionnaires were administered face-to-face in both central (62\%) and suburban areas (38\%). The number of questionnaires allocated to each area was probabilistically related to population (systematic random selection approach): for example the five largest communities comprising 39,783; 23,391; 23,151; 20,447 and 16,992 inhabitants, were allocated 172; 102; $99 ; 98$ and 87 questionnaires respectively; the five smallest communities, comprising 418, 636, 685, 835, and 840 inhabitants, were allocated $2,4,4,4$ and 4 questionnaires respectively.

\subsection{Measures}

\subsubsection{Socio-demographic variables}

The questionnaire asked about gender $(0=$ female; $1=$ male $)$, 
age (as a continuous variable), educational level and professional situation. Participants were asked to indicate the highest level of education completed.

\subsubsection{Satisfaction with the quality of the recycling service}

A short version of SERVQUAL-a service quality scale (Parasuraman et al., 1988)—was used to measure participants' satisfaction with their recycling service. Residents were asked to identify their level of satisfaction with the recycling company in relation to eight items (e.g. providing services at the promised times; The eight items are supplied in the Supplementary Table 1), using a five-point Likert scale, where $1=$ 'highly dissatisfied' and 5 = 'totally satisfied'. Cronbach's alpha for the scale was 0.91 .

\subsubsection{Self- and community efficacy with respect to recycling behaviour}

The participants' perceptions of their own and their community's efficacy with respect to specific recycling activities were evaluated using three items: (1) To what extent do you feel that you are capable of separating all the paper and cardboard generated in your home and taking it to its respective container?; (2) To what extent do you feel that you are capable of separating all the glass, etc.?; (3) To what extent do you feel that you are capable of separating all the packaging, etc.? This measurement of self- and community efficacy drew on work by Bandura (2006). Participants were asked to register their confidence using a ten-point Likert scale where $1=$ 'not at all confident' and $10=$ 'totally confident'. Cronbach's alpha for the scale was 0.91 . To confirm the validity of the aggregation method of assessing community efficacy we tested whether averages scores differed significantly across communities using a oneway ANOVA with self-efficacy as the dependent variable ( $F(54$, $1446)=1.397 ; p<0.05)$; the group difference indicated that the aggregation method was appropriate.

\subsubsection{Individual recycling behaviours}

In order to assess recycling behaviour, three items were used to evaluate the extent to which individuals recycled paper, glass and packaging: (1) Do you separate paper and cardboard from the rest of the waste?; (2) Do you separate glass from the rest of the waste?; (2) Do you separate plastics, cans and cartons from the rest of the waste? The participants gave their answers on a five-point Likert scale, where $1=$ 'never' and 5 = 'always'. A single variable was created using the mean score for all three self-reported behaviours. Cronbach's alpha for this measure was 0.84 .

\subsubsection{Community recycling rate}

Finally, data from the local recycling company (kilograms of paper and glass recycled per resident per year) were used as an objective index of the amount of waste recycled in each locality. The correlation between measures of paper and glass recycling was high $(r=0.43, p<0.001)$, so a single measure of observable recycling behaviour was created for each of the 55 localities: total amount of material recycled per year, divided by number of households.

\subsection{Data analysis}

In order to test our predictions, we estimated a series of multilevel random models (See Supplementary Table 2) using the Hierarchical Linear and Nonlinear Modelling (HLM) software (version 6.08; Raudenbush et al., 2005).

First, we ran an intercept-only model (Model 0) to describe how much of the total variance in recycling is allocated to each level of analysis; we used this to calculate the intra-class correlation and the explained variance in subsequent models. We then estimated five models, including two levels. The level 1 models estimated the relationship of the control variables (sex, age and education; Model 1: H1a, H1b, and H1c) and individual predictors (satisfaction with service quality, individual efficacy; Model 2: H2 and H3) with the outcome variable (recycling). The level 2 models added the estimation of the associations between the contextual predictors (community efficacy, number of inhabitants, community recycling rate; Model 3: $\mathrm{H} 4, \mathrm{H} 5$, and $\mathrm{H} 6$ ). We also estimated a model including individual, collective and cross-level two- and three-way interactions (Models 4 and 5: H7, H8, and H9), aiming to test specific hypotheses about the conditional effect of individual and contextual predictors on recycling behaviour. We attributed weighted effect codes for the categorical predictor (sex: male $=-0.48$; female $=0.57$ ) and all continuous predictors were grand mean-centred in order to facilitate the interpretation of main and conditional effects (Aiken and West, 1991; Judd et al., 2009; Nezlek, 2001). Finally, models were estimated as either fixed or random error terms based on statistical significance in the preliminary analyses, to ensure convergence (Nezlek, 2001). The equations corresponding to each estimated model are provided in the Supplementary Table 2.

\section{Results}

Correlations between recycling and age, satisfaction with service quality, and self-efficacy with respect to recycling were in the predicted direction, but there was no correlation between recycling and educational level. The correlational analyses also confirmed the predicted relationship between self-efficacy and self-reported recycling behaviour $(r=0.268, p<0.05)$ and between our objective measure of recycling (kilograms of paper and glass recycled per resident per year) and self-efficacy $(r=0.320, p<0.05)$. The individual and collective level descriptive statistics and correlations are available in the Supplementary Table 3.

The multilevel hypotheses tests are summarised in the Supplementary Table 2 (see 3.5 ). The parameters estimated in Model 1 indicated that only participants' ages (H1a) and educational level (H1c) explained recycling behaviour, and demonstrated that the control variables have a weak relationship with recycling, explaining only about $1 \%$ of the variance at level 1 . Model 2 showed that both satisfaction with service quality (H2) and self-efficacy (H3) explained recycling behaviour and increased the explained variance to about $45 \%$ at level 1 . As we had predicted, the greater the perceived efficacy and satisfaction the more participants are involved in recycling. The Model 3 results showed that the relationship between the individual variables remained significant even after adding the three predictors at level 2. Despite explaining $50 \%$ of the variance at this level, only number of inhabitants reliably predicted recycling behaviour (H5): larger number of inhabitants was associated with lower levels of individual recycling. The results of Model 4 indicated two reliable cross-level interactions: community efficacy functions moderated the effects of self-efficacy and satisfaction with the recycling service quality on recycling behaviour. Self-efficacy had less effect on recycling in localities with higher community efficacy. Satisfaction had a greater effect on recycling in localities with higher community efficacy. Importantly, the results of Model 5 demonstrated that these interactions are qualified by three-way interactions: the interaction between selfand community efficacy depended on community recycling rate (H7) and the interaction between satisfaction and community efficacy depended on population (H8). Model 5 also revealed a reliable three-way cross-level interaction between satisfaction, number of inhabitants and community recycling rate (H9). This final model explained $45 \%$ of the variance at the individual level and $55 \%$ at the collective level. The Supplementary Figs. S1-S3 
decompose the interaction effects and clarify the relationship between specific individual and collective variables and recycling.

The cross-level interaction effect between self- and community efficacy on recycling (Supplementary Fig. S1) was not reliable in localities with low community recycling rates $(\gamma=-0.037$; $\mathrm{SE}=0.037, t=-1.00, n s$.), so self-efficacy predicted recycling when community efficacy was low $(\gamma=0.312$; $\mathrm{SE}=0.031, t=9.93$, $p<0.001)$ and when it was high $(\gamma=0.273$; SE $=0.037, t=7.21$, $p<0.001)$. However, the cross-level interaction was reliable in localities with high community recycling rates $(\gamma=-.199$; $\mathrm{SE}=0.034, t=-5.72, p<0.001)$. Self-efficacy had a greater effect on recycling when community efficacy was low $(\gamma=0.382$; $\mathrm{SE}=0.036, t=10.54, p<0.001)$ than when it was high $(\gamma=0.175$; $\mathrm{SE}=0.027, t=6.42, p<0.001)$.

The cross-level interaction between satisfaction and community efficacy on recycling (Supplementary Fig. S2) was not reliable in localities with a small population $(\gamma=-.009$; SE $=0.105$, $t=-0.082, n s$, see Supplementary Fig. S2a): satisfaction with service quality was positively associated with recycling when community efficacy was low $(\gamma=0.297 ; \mathrm{SE}=0.106, t=2.73, p<0.01)$ and when it was high $(\gamma=0.273$; SE $=0.101, t=2.69, p<0.01)$. However, the cross-level interaction was reliable in localities with a larger population $(\gamma=0.189 ; \mathrm{SE}=0.052, t=3.65, p<0.001$, see Supplementary Fig. S2a), indicating that satisfaction with service quality affected recycling when community efficacy was high $(\gamma=0.449 ; \mathrm{SE}=0.058, t=7.68, p<0.001)$, but not when it was low $(\gamma=0.053 ; \mathrm{SE}=0.059, t=0.89, n s$.$) .$

The cross-level interaction between satisfaction and community recycling rate (Supplementary Fig. S3) was reliable in localities with a small population (population $\leq \mathrm{M}-\mathrm{SD} ; \gamma=-.005$; $\mathrm{SE}=0.001$, $t=-3.45, p<0.001$ ) and a large population (population $\geq \mathrm{M}+\mathrm{SD}$; $\gamma=-.004$; SE $=0.002, t=-2.13, p<0.05$ ). Satisfaction with the service had a greater effect on recycling when the community recycling rate was high (Supplementary Fig. S3a; $\gamma=0.349$; $\mathrm{SE}=0.058, t=6.06, p<0.001)$ than when it was low $(\gamma=0.214$; $\mathrm{SE}=0.063, t=3.90, p<0.001)$ in localities with a small population. A different pattern emerged in localities with a large population (Supplementary Fig. S3b): satisfaction with the service had a greater effect on recycling when community recycling rate was low $(\gamma=0.317 ; \mathrm{SE}=0.023, t=13.78, p<0.001)$ than when it was high $(\gamma=0.185 ; \mathrm{SE}=0.056, t=3.31, p<0.001)$.

\section{Discussion}

The results of this study show that in those communities in which citizens share a strong belief in their ability to recycle, individuals engage in a greater number of recycling behaviours in their communities. These results may be generalized to other international contexts because we emphasize the relevance of strong perceptions of community efficacy independently of individual differences. Our explanatory model for environmental behaviour highlights the importance of the combination of a high-quality recycling service and strong perceptions of community efficacy in driving other self-regulatory mechanisms-e.g. self-efficacy-on behaviour. The importance of this study also lies in its use of a multilevel approach; objective measures of community recycling and self-reported community efficacy with respect to recycling were considered as collective variables in 55 localities. The relationship observed in this study between these collective variables and individual variables (age, educational level, satisfaction service quality, self-efficacy) suggests that community profile and an index of motivation could account for community environmental behaviour. It can be highlighted that the large number of localities surveyed are highly heterogeneous, and thus may allow generalization to other international communities.
Like previous studies that compared eco-friendly attitudes in European citizens (Pirani and Secondi, 2011), the results support the hypothesis that the age and educational level are related to recycling behaviour (see $\beta$ scores of Model 1 in the Supplementary Table 2): older people and individuals with a higher educational level recycle most. However, like Guerin et al. (2001), we found that socio-demographic variables had a modest relationship with recycling behaviour and explained only a small percentage of the variance compared with other motivational variables such as selfefficacy and satisfaction with the quality of the service, such that these significant relationships disappeared when other variables were inserted into the models. This modest effect was also found in the correlational analysis, in which age, but not educational level, was significantly associated with recycling behaviour. Those results seem to indicate that international policies and campaigns oriented to promote environmentally responsible behaviour regarding citizenships should accentuate their actions to younger people and individuals with lower educational levels.

One of the contributions our study makes to the literature is our exploration of the interactions between individual and collective variables e.g. community efficacy. We found that satisfaction with the service was more strongly related to recycling behaviour in communities with a greater awareness of community efficacy with respect to recycling. Bandura (1997) and Caprara and Steca (2007) claimed that shared judgments by members of a community, about their community's capacity to carry out an act, are the major cause of social change. Our results suggest areas on which national and international environmental policies should focus in order to increase recycling in communities: encouraging a belief in selfefficacy with respect to recycling and promoting the belief that the community can make environmentally-friendly changes in the future; maintaining common goals along these lines; helping individuals feel satisfied with the recycling behaviours developed. In this way, community efficacy should affect individual behaviour through a process of social comparison - the perceived social norm influences individuals' behaviour. This argument was made in one of the most influential theories of environmental psychology, the Norm Activation Model (NAM; Schwartz and Howard, 1981), which stated that personal moral norms are determinants of intention to behave pro-environmentally. Extending these ideas Goddard and Goddard (2001) explained how collective efficacy, through its effect on community behavioural norms, can affect both self-efficacy and individual behaviour. From a socio-cognitive point of view, community efficacy and community recycling rates exert a powerful normative pressure that may be understood social persuasion by the community as a whole with respect to both selfefficacy and individual recycling rate. The proposition that community recycling rate can influence individual recycling rates is interesting, and important from a social norms perspective; future research in this field could analyse how community recycling norms affect individuals' recycling behaviour at the international level.

As Blake (1999) suggested, our research also supports the interest in working towards the creation of more sustainable communities. In Blake's (1999) study participants expressed a willingness to be involved in local activities aimed at building a sense of community to promote ERB; in our study community efficacy with respect to recycling was related to community recycling rate.

The present multilevel analysis highlights the important role that population plays in perceived community efficacy; the larger the community, the less individuals recycle. Kerr (1989) demonstrated that although group size was objectively irrelevant to individual behaviour in a social dilemma, members of small groups experienced a higher level of self-efficacy than members of larger 
groups. Furthermore, in an analysis of the effect of group size on perceptions of community efficacy, Kerr (1989) found that when a high proportion (67\%) of group members demonstrated their contribution to the behaviour required to achieve a common goal, group size did not have a significant effect on perceived collective efficacy, instead perceived collective efficacy was directly associated with community performance. It is interesting that this study has provided an illustration of the tendency for smaller communities to have greater community efficacy with respect to development of pro-environmental initiatives than larger communities. Once more, local, national and international policies and campaigns oriented to promoting environmentally responsible behaviour must take into account those finding making a greater effort in the larger community when implementing their actions.

With regard to future research, the results presented here suggest that it would be interesting to analyse the role of leadership in developing collective beliefs that would motivate pro-social behaviour, specifically pro-environmental behaviour. This study did not consider the role of leadership figures in the community, but our results showed the importance of generating community behaviours; this can be related to Lindsley et al.'s (1995) view that social change is a product of the efficacy-performance spirals in individuals, groups, communities and organisations. As social role models, leaders transmit values, knowledge, cognitive skills, coping styles, behavioural styles and lifestyles (Bandura, 1997). They can also transmit emotional states to others or transfer their emotional state to the surrounding context when others observe how they interact with their surroundings. Levels of personal motivation, affective states and actions are grounded in individuals' beliefs about what they can achieve rather than in what they actually achieve in a specific situation.

Previous research has demonstrated that one of the most effective strategies for increasing perceived community efficacy is to increase the number of acts directed towards a common purpose (Bandura, 1997). In organisational contexts, Gibson and Earley (2007) found that when leaders and communities have a greater sense of group efficacy, individual performance is enhanced. Furthermore, there is also evidence (Portugal and Yukl, 1994) that transformational leadership determines pro-environmental community behaviour. Future studies should investigate the mediating effect of perceived community efficacy on the relationship between leadership and community behaviour. Staats, Harland, and Wilke (2004) carried out a community intervention, increasing provision of environmental information, generating feedback and creating social interactions in order to achieve long-lasting changes in domestic pro-environmental behaviour (saving water and recycling). However, Homburg and Stolberg (2006) claimed that community efficacy plays a more important role in proenvironmental behaviour than self-efficacy.

\subsection{Limitations of this study and proposals for future research}

Certain limitations of the present research can be identified. Some variables were measured using self-report scales; however these scales had high reliability and there was a high positive correlation between self-reported recycling behaviour and an objective measure of the amount of material recycled (kilograms of paper and glass recycled per resident) by each community. CorralVerdugo and Figueredo (1999) found a relationship between selfreported re-usage and direct observations of re-use. This confirmed the validity of their assessment of conservation behaviour. We aggregated individuals' reports of efficacy (using items such as To what extent do you feel that you are capable of separating all the paper and cardboard generated in your home and taking it to its respective container?; To what extent do you feel that others in your town are capable ... ?; To what extent do you believe your community is capable ... ?) to obtain a measure of community efficacy; an alternative method would be to use a consensus measure obtained using more qualitative techniques e.g. focus groups. However, our choice of a questionnaire method of evaluating community efficacy allowed us to index perceived community efficacy in large samples, and has the additional advantage of offering an easy way of estimating changes in community efficacy over time. Israel, Checkoway, Schulz and Zimmerman (1994) have advocated the simultaneous use of qualitative and quantitative methods to measure community perceptions in multilevel designs.

A second limitation relates to the representativeness of our sample, which had higher percentage of women $(72.1 \%$ against to $50.88 \%$ in the actual population), and people younger than 30 years (29.92\% against to $22.34 \%$ ) and a lower percentage of people between 31 and 50 years (28.75\% against to $37.41 \%$ ) than the population as a whole. The gender imbalance may have been due to the high unemployment rate for women $(33.06 \%$ compared to $29.80 \%$ for men) and young Spanish people (55.09\% compared to $28.71 \%$ in people over 25 years old). It may be that unemployed women and young people were more likely to be home, whereas people between 31 and 50 years were probably at work; we surveyed participants at home and this may account for the over-representation of women and young people in our sample. We sampled communities using random selection, with sample size probabilistically related to population such that in each community approximately $0.04 \%$ of the population was surveyed. For the five smallest communities, with only 400-1000 inhabitants, this may have made the use of aggregated individual-level data on self-efficacy to provide a measure of community efficacy problematic. In the smallest town (410 inhabitants), only 2 residents were interviewed to represent the entire population and in four other communities with 636,685 , 835 , and 840 inhabitants respectively, only 4 residents were surveyed. This limitation affected only the smallest five of fifty-five communities, 18 out of 1501 participants (1.2\% of the sample) and should not have affected the results of the study. Nevertheless, since some of the results of the study were related to effects of community size, it would be of interest to investigate community processes in small communities, because number of inhabitants may be negatively associated with community efficacy.

A third limitation is related to other variables that we have not evaluated which may act as co-variates. Although, as we predicted and these results confirmed, there is a significant association between satisfaction with the quality of the service and recycling, we cannot rule out the possibility that this association is due to covariates which we did not measure or is mediated by other unmeasured variables such as perceived or actual barriers to recycling. We would expect that communities that make it easy for individuals to recycle are likely to elicit both higher satisfaction levels and higher rates of recycling. However we did not find a correlation between the numbers of containers for recycling paper $(r=-.17 ; p>0.05)$ and glass $(r=-.17 ; p>0.05)$ and recycling rates. Given that the number of recycling containers in a community is significantly correlated with number of inhabitants (glass: $r=0.98$; $p<0.001$, paper: $r=0.95$; $p<0.001$ ) facilities are similar across communities and the variability in number of recycling containers did not explain the differences in recycling rates. It would therefore be interesting to explore other variables that may be involved in the association between satisfaction with the service and recycling rates. Previous research has showed that a range of other variables can influence recycling: living in a single family household, owning one's own home, and having neighbours and friends who recycle a lot were associated with higher recycling levels (Oskamp et al., 1991). In addition, Berger (1997) demonstrated that size of residential area, type of dwelling, and income act as determinants of 
facilities to support recycling. The relationship between community size and individuals' decisions about recycling may require further consideration. It could be argued that certain barriers to recycling are more common in larger communities, and that these particular barriers may be critical to the decision on recycling. If this were the case, individuals belonging to smaller communities would be more likely to decide to recycle because they would face fewer barriers to recycling. Emphasizing the interest of this study to the international scientific community it might be interesting, in future studies, to explore which other variables are involved in the relationship between community size and an individual's decisions regarding recycling.

We have shown that satisfaction with the quality of the service is related to recycling behaviour. Understandably, even within a single organisation, service quality may differ (e.g. a single organisation may offer the same service but workers might differ in their interest in solving problems, willingness to help, or in providing the necessary information, etc.; all aspects of service quality assessed by the measure we used), and in turn satisfaction with the quality of the service may be affected. We therefore suggest that in future studies it would be interesting to include objective measures of quality of the recycling service (e.g. frequency of pickup, number of complaints) and the recycling behaviour of service users (e.g. amount of contamination of recycled materials) in order to analyse how these variables influence recycling at individual and community levels. In this sense, future research should explore other factors related to communication campaigns oriented to the managed use of waste.

\subsection{Conclusions and practical implications}

In summary, this research contributes to a better understanding of the effects of motivational variables on recycling behaviour. The findings of this study highlight the importance of developing selfand community efficacy within a population and maintaining a high level of satisfaction with the quality of the recycling service offered to the community. At a practical level and regarding the national and international environmental policies and politics, it would therefore be useful to create environmental education programmes and publicity campaigns, specifically adapted to different contexts (work, home and leisure) with the aim of improving perceptions of community efficacy with respect to environmental behaviour. Based on this study, we suggest that interventions should target individuals and communities e.g. increase perceived self- and community efficacy and improve community attachment and communication within the community. Bandura (1997) claimed that a strong leader may be able to "unite the community for a common cause" (p. 501) and our results lead us to suggest that a strong leader with high self-efficacy with respect to recycling behaviour may help to build collective efficacy with respect to recycling. We suggest that community organisations and leadership might be harnessed to enhance individuals' self-efficacy with respect to recycling.

But how can we design a pro-environmental training programme to influence personal and community judgments of efficacy? Bandura (1997) showed that it is necessary to combine three elements in such programmes: (i) promotion of essential basic skills by establishing a series of rules and operational strategies via an instructive model or training programme in a specific context-Oskamp et al. (1991) demonstrated the effect on recycling of modelling by friends and neighbours'; (ii) trainees should use simulation practice, which is related to their actual performance, to develop their confidence in their own capabilities-Ahn (2011) conducted a series of experiments with an immersive virtual environment technology' to demonstrate that experimentation with this virtual experience can increase self-efficacy and proenvironmental behaviours in participants; (iii) pro-environmental situations in which trainees can practise and transfer the skills learned in order to increase their sense of achievement and perceived control of their capabilities. Following this logic, some of Cordoba's localities organised an environmental training day for their citizens making use of the instructions published at www. cleanuptheworld.com/es/. Environmental programmes should aim to create among citizens confidence in their community's ability to carry out specific actions that will help to protect the environment. Such interventions would improve satisfaction with the public organisations responsible for waste management.

\section{Funding}

The authors disclosed receipt of the following financial support for the research and/ or authorship of this article: This article was based on two research projects supported by the Spanish Ministry of Science and Technology under Grants PSI2009-07423, PSI201458609-R and PSI2009- 08896 in which Carmen Tabernero and Bernardo Hernández are the main researchers, respectively.

\section{Appendix A. Supplementary data}

Supplementary data related to this article can be found at http:// dx.doi.org/10.1016/j.jenvman.2015.05.024.

\section{References}

Ahn, S.J., 2011. Embodied Experiences in Immersive Virtual Environments: Effects on Pro-environmental Attitude and Behavior. Stanford University available at: \% 3ca href=http://vhil.stanford.edu/pubs/2011/ahn-embodied-experiences.pdf.

Aiken, L.S., West, S.G., 1991. Multiple Regression: Testing and Interpreting Interactions. Sage, Newbury Park, CA.

Bamberg, S., Möser, G., 2007. Twenty years after Hines, Hungerford, and Tomera: a new meta-analysis of psycho-social determinants of pro-environmental behaviour. J. Environ. Psychol. 27, 14-25. http://dx.doi.org/10.1016/ j.jenvp.2006.12.002.

Bandura, A., 1997. Self-efficacy: The Exercise of Control. Freeman, New York.

Bandura, A., 2000. Exercise of human agency through collective efficacy. Curr. Dir. Psychol. Sci. 9 (3), 75-78. http://dx.doi.org/10.1111/1467-8721.00064.

Bandura, A., 2002. Environmental sustainability by sociocognitive deceleration of population growth. In: Schmuch, P., Schultz, W. (Eds.), The Psychology of Sustainable Development. Kluwer, Dordrecht, The Netherlands, pp. 209-238.

Bandura, A., 2006. Guide to the construction of self-efficacy scales. In: Pajares, F., Urdan, T. (Eds.), Self-efficacy Beliefs of Adolescents, vol. 5. Information Age Publishing, Greenwich, CT, pp. 307-337.

Berger, I.E., 1997. The demographics of recycling and the structure of environmental behavior. Environ. Behav. 29 (4), 515-531. http://dx.doi.org/10.1177/ 001391659702900404.

Blake, J., 1999. Overcoming the 'value-action gap' in environmental policy: tensions between national policy and local experience. Local Environ. 4, 257-278. http:// dx.doi.org/10.1080/13549839908725599.

Bruhn, M., Georgi, D., 2006. Services Marketing: Managing the Service Value Chain. Pearson Education, Harlow.

Caprara, G.V., Steca, P., 2007. Prosocial agency: the contribution of values and selfefficacy beliefs to prosocial behavior across ages. J. Soc. Clin. Psychol. 26, 218-239. http://dx.doi.org/10.1521/jscp.2007.26.2.218.

Chen, M.F., Tung, P.J., 2010. The moderating effect of perceived lack of facilities on consumers' recycling intentions. Environ. Behav. 42 (6), 824-844. http:/ dx.doi.org/10.1177/0013916509352833.

Chen, X., Peterson, M.N., Hull, V., Lu, C., Hong, D., Liu, J., 2013. How perceived exposure to environmental Harm influences environmental behavior in urban China. Ambio 42 (1), 52-60. http://dx.doi.org/10.1017/S037689291000086X.

Cialdini, R.B., Demaine, L.J., Sagarin, B.J., Barrett, D.W., Rhoads, K., Winter, P.L., 2006 Managing social norms for persuasive impact. Soc. Influ. 1, 3-15. http:// dx.doi.org/10.1080/15534510500181459.

Cialdini, R.B., Reno, R.R., Kallgren, C.A., 1990. A focus theory of normative conduct: recycling the concept of norms to reduce littering in public places. J. Personality Soc. Psychol. 58, 1015-1026. http://dx.doi.org/10.1037//0022-3514.58.6.1015.

Corral-Verdugo, V., 2012. The positive psychology of sustainability. Environ. Dev. Sustain. 14, 651-666. http://dx.doi.org/10.1007/S10668-012-9346-8.

Corral-Verdugo, V., Figueredo, A.J., 1999. Convergent and divergent validity of three measures of conservation behavior. The multitrait-multimethod approach. Environ. Behav. $31 \quad$ (6), 805-820. http://dx.doi.org/10.1177/ 00139169921972353. 
Corral-Verdugo, V., Frías-Armenta, M., Pérez-Urías, F., Orduña-Cabrera, V., EspinozaGallego, N., 2002. Residential water consumption, motivation for conserving water, and the continuing tragedy of commons. Environ. Manag. 30 (4), 527-535. http://dx.doi.org/10.1007/s00267-002-2599-5.

Gelissen, J., 2007. Explaining popular support for environmental protection. A multilevel analysis of 50 nations. Environ. Behav. 39, 392-441. http:// dx.doi.org/10.1177/0013916506292014.

Gellynck, X., Jacobsen, R., Verhelst, P., 2011. Identifying the key factors in increasing recycling and reducing residual household waste: a case study of the Flemish region of Belgium. J. Environ. Manag. 92 (10), 2683-2690. http://dx.doi.org/10. 1016/j.jenvman.2011.06.006.

Gibson, C.B., 2003. The efficacy advantage: factors related to the formation of group efficacy. J. Appl. Psychol. 33 (10), 2153-2186. http://dx.doi.org/10.1111/j.15591816.2003.tb01879.x

Gibson, C.B., Earley, P.C., 2007. Collective cognition in action: accumulation, interaction, examination and accommodation in the development and operation of group efficacy beliefs in the workplace. Acad. Manag. Rev. 32, 438-458. http:// dx.doi.org/10.5465/AMR.2007.24351397.

Gifford, R., 2013. Environmental psychology that matters. Annu. Rev. Psychol. 65 (1) http://dx.doi.org/10.1146/annurev-psych-010213-115048.

Gist, M.E., 1987. Self-efficacy: implications for organizational behavior and human resource management. Acad. Manag. Rev. 12, 472-485. http://dx.doi.org 10.5465/AMR.1987.4306562.

Goddard, R.D., Goddard, Y.L., 2001. A multilevel analysis of the relationship between teacher and collective efficacy in urban schools. Teach. Teach. Educ. 17 (7), 807-818. http://dx.doi.org/10.1016/S0742-051X(01)00032-4.

Grönroos, C., 1984. A service quality model and its marketing implications. Eur. J. Mark. 18, 35-44. http://dx.doi.org/10.1108/EUM0000000004784.

Guerin, D., Crete, J., Mercier, J., 2001. A multilevel analysis of the determinants of recycling behavior in the European countries. Soc. Sci. Res. 30, 195-218. http:// dx.doi.org/10.1006/ssre.2000.0694.

Hernández, B., Martín, A., Ruiz, C., Hidalgo, M.C., 2010. .The role of place identity and place attachment in breaking environmental protection laws. J. Environ. Psychol. 30, 281-288. http://dx.doi.org/10.1016/j.jenvp.2010.01.009.

Homburg, A., Stolberg, A., 2006. Explaining pro-environmental behavior with a cognitive theory of stress. J. Environ. Psychol. 26, 1-14.

Israel, B.A., Checkoway, B., Schulz, A., Zimmerman, M., 1994. Health education and community empowerment: conceptualizing and measuring perceptions of individual, organizational, and community control. Health Educ. Behav. 21 (2), 149-170. http://dx.doi.org/10.1177/109019819402100203.

Jordan, A., Lenschow, A., 2010. Policy paper. Environmenal policy integration: a state of the art review. Environ. Policy Gov. 20, 147-158.

Juárez-Lugo, C., 2010. Predictors of recycling behavior among primary school students in Mexico. Psyecology 1, 91-103. http://dx.doi.org/10.1174/ 217119710790709586.

Judd, C.M., McClelland, G.H., Ryan, C.S., 2009. Data Analysis: a Model Comparison Approach, second ed. Routledge Press, New York.

Kerr, N.L., 1989. Illusion of efficacy: the effect of group size on perceived efficacy in social dilemmas. J. Exp. Soc. Psychol. 25, 287-313. http://dx.doi.org/10.1016/ 0022-1031(89)90024-3.

Kollmuss, A., Agyeman, J., 2002. Mind the gap: why do people act environmentally and what are the barriers to pro-environmental behaviour. Environ. Educ. Res. 8, 239-260. http://dx.doi.org/10.1080/13504620220145401.

Lindsley, D.H., Brass, D., Thomas, J.B., 1995. Efficacy-performance spirals: a multilevel perspective. Acad. Manag. Rev. 20, 645-678. http://dx.doi.org/10.5465/ AMR.1995.9508080333.

Martín, A., Hernández, B., Frías-Armenta, M., Hess, S., 2014. Why ordinary people comply with environmental laws: a structural model on normative and attitudinal determinants of illegal anti-ecological behaviour. Leg. Criminol. Psychol.
19 (1), 80-103. http://dx.doi.org/10.1111/j.2044-8333.2012.02062.x.

Milfont, T.L., Page, E., 2013. A bibliometric review of the first thirty years of the Journal of Environmental Psychology. Psyecology 4, 195-216.

Nezlek, J.B., 2001. Multilevel random coefficient analyses of event- and intervalcontingent data in social and personality psychology research. Personality Soc. Psychol. Bull. 27, 771-785. http://dx.doi.org/10.1177/0146167201277001.

National Statistics Institute, 2013. Demography and Population. http://www.ine.es/ en/censos2011_datos/cen11_datos_inicio_en.htm.

Osbaldiston, R., Schott, J.P., 2012. Environmental sustainability and behavioural science: meta-analysis of proenvironmental behaviour experiments. Environ. Behav. 44, 257-299. http://dx.doi.org/10.1177/0013916511402673.

Oskamp, S., 2002. Environmentally responsible behavior: teaching and promoting it effectively. Analyses Soc. Issues Public Policy 2, 173-182. http://dx.doi.org/ 10.1111/j.1530-2415.2002.00036.x.

Oskamp, S., Harrington, M.J., Edwards, T.C., Sherwood, D.L., Okuda, S.M., Swanson, D.C., 1991. Factors influencing household recycling behavior. Environ. Behav. 23 (4), 494-519. http://dx.doi.org/10.1177/0013916591234005.

Parasuraman, A., Zeithaml, V.A., Berry, L.L., 1988. SERVQUAL: a multi-item scale for measuring consumer perceptions of service quality. J. Retail. 64, 12-40.

Pirani, E., Secondi, L., 2011. Eco-friendly attitudes: what European citizens say and what they do. Int. J. Environ. Res. 5 (1), 67-84.

Portugal, E., Yukl, G., 1994. Perspectives on environmental leadership. Leadersh. Q. 5, 271-276. http://dx.doi.org/10.1016/1048-9843(94)90017-5.

Raudenbush, S., Bryk, A., Congdon, R., 2005. HLM 6: Hierarchical Linear and Non Linear Modeling. Scientific Software International, Lincolnwood, IL.

Reicheld, F.F., 1996. The Loyalty Effect. Harvard Business School Press, Boston.

Sampson, R.J., Raudenbush, S.W., Earls, F., 1997. Neighborhoods and violent crime: a multilevel study of collective efficacy. Science 277, 918-924. http://dx.doi.org/ 10.1126/science.277.5328.918.

Scannell, L., Gifford, R., 2013. Personally relevant climate change: the role of place attachment and local versus global message framing in engagement. Environ. Behav. 45 (1), 60-85. http://dx.doi.org/10.1177/0013916511421196.

Schultz, P.W., Bator, R.J., Large, L.B., Bruni, C.M., Tabanico, J.J., 2013. Littering in context: personal and environmental predictors of littering behaviour. Environ. Behav. 45, 35-59. http://dx.doi.org/10.1177/0013916511412179.

Schwartz, S.H., Howard, J.A., 1981. A normative decision-making model of altruism. In: Altruism and Helping Behavior, pp. 189-211.

Staats, H., Harland, P., Wilke, H.A.M., 2004. Effecting durable change. A team approach to improve environmental behavior in the household. Environ. Behav. 36, 341-367. http://dx.doi.org/10.1177/0013916503260163.

Steg, L., Gifford, R., 2005. Sustainable transport and quality of live. J. Transp. Geogr. 13 (1), 59-69. http://dx.doi.org/10.1016/j.jtrangeo.2004.11.003.

Tabernero, C., Hernández, B., 2011. Self-Efficacy and intrinsic motivation guiding environmental behavior. Environ. Behav. 43, 658-675. http://dx.doi.org/ 10.1177/0013916510379759.

Tabernero, C., Hernández, B., 2012. A motivational model for environmentally responsible behavior. Span. J. Psychol. 15 (2), 648-658.

Turaga, R.M., Howarth, R.B., Borsuk, M.E., 2010. Pro-environmental behavior. Rational choice meets moral motivation. Ann. New Acad. Sci. Issue Ecol. Econ. Rev. 1185, 211-224. http://dx.doi.org/10.1111/j.1749-6632.2009.05163.x.

Vining, J., Ebreo, A., 1990. What makes a recycler? A comparison of recyclers and nonrecyclers. Environ. Behav. 22, 55-73. http://dx.doi.org/10.1177/ 0013916590221003.

Watson, C.B., Chemers, M.M., Preiser, N., 2001. Collective efficacy: a multilevel analysis. Personality Soc. Psychol. Bull. 27 (8), 1057-1068. http://dx.doi.org/ $10.1177 / 0146167201278012$.

Zaccaro, S.J., Blair, V., Peterson, C., Zazanis, M., 1995. Collective efficacy. In: Maddux, J. (Ed.), Self-efficacy, Adaptation and Adjustment: Theory, Research, and Application. Plenum Press, New York, NY, pp. 305-328. 